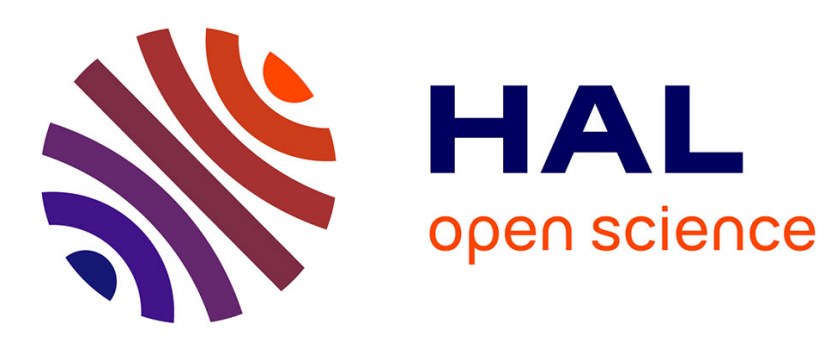

\title{
Sizing of the Physical Layer of a RF Intra-Chip Communications
}

Mohamad Hamieh, Myriam Ariaudo, Sébastien Quintanel, Yves Louët

\section{To cite this version:}

Mohamad Hamieh, Myriam Ariaudo, Sébastien Quintanel, Yves Louët. Sizing of the Physical Layer of a RF Intra-Chip Communications. ICECS, Dec 2014, marseille, France. hal-01091652

\section{HAL Id: hal-01091652 \\ https://hal.science/hal-01091652}

Submitted on 8 Dec 2014

HAL is a multi-disciplinary open access archive for the deposit and dissemination of scientific research documents, whether they are published or not. The documents may come from teaching and research institutions in France or abroad, or from public or private research centers.
L'archive ouverte pluridisciplinaire HAL, est destinée au dépôt et à la diffusion de documents scientifiques de niveau recherche, publiés ou non, émanant des établissements d'enseignement et de recherche français ou étrangers, des laboratoires publics ou privés. 


\section{Sizing of the Physical Layer of a RF Intra-Chip Communications}

\author{
Mohamad HAMIEH, Myriam ARIAUDO, Sébastien \\ QUINTANEL. \\ ETIS/ ENSEA- University of Cergy-Pontoise - CNRS \\ F-95000,Cergy-Pontoise, France \\ mohamad.hamieh@ensea.fr, sebastien.quintanel@ensea.fr, \\ myriam.ariaudo@ensea.fr
}

\author{
Yves LOUET. \\ IETR/ SUPELEC-CNRS \\ F-35576 Cesson-Sévigné Cedex, France \\ yves.louet@supelec.fr
}

\begin{abstract}
In this paper we size a RF intra-chip communications based on Orthogonal Frequency Division Multiple Access (OFDMA) modulation which allows data rate and message recipient reconfiguration. Firstly, we present the advantages of this modulation such as providing flexible and high-speed data transmission. Then, we study the impact of the RF-interconnect channel shape on the transmission in terms of required transmission power. Finally, we present the effect of the channel composed of the line and its multiple access on the transfer of information and we perform a channel equalization to overcome this undesired effect.
\end{abstract}

Keywords-RF-NoC; OFDMA modulation; Transmission optimization.

\section{INTRODUCTION}

The technological progress in the design of system on Chip (SoC) is to integrate a very large number of processing elements and memories on a single chip leading to the rise of MultiProcessor System on Chip (MPSoC). Such an advanced integration allows to envisage powerful electronic systems that may offer a large number of services such as high bit rate, high speed transmission, etc. However these architectures put up new challenges for the interconnections between the processing units. The scaling up will impact heavily on the performance of global interconnections in terms of latency, flow rate and consumption. In this context, many integration technologies have been involved, like 3D [1], optical [2] and/or RF (Radio Frequency) [3][4][5] interconnect architectures. The interconnect between the Processing Elements (PE) in the same Network on Chip (NoC) through the RF approach, could benefit from high compatibility with the Silicium technology [6]. In an integrated circuit, RF communications can either be wireless (antennas communications [7]) or through a transmission line [4]. In our paper, we consider the case where the transmission is provided through a transmission line.

In this context, as described in [8] we propose to develop a hierarchical communication scheme for which a flexible RF interconnect is used to communicate between distant clusters of a single chip. Each of these clusters contains a wired NoC, whose processors communicate between each others by conventional buses, and a transmitter/receiver (Tx/Rx) system for the transmission with other distant clusters via a waveguide (RF transmission line)(fig.1).
To allow the flexibility of transmissions, we have proposed an allocation of spectrum resources based on an Orthogonal Frequency Division Multiple Access (OFDMA) modulation which introduces essential advantages such as reducing the number of RF components and digital reconfigurability and allocation of subcarriers.

In this paper, we analyse the physical layer of this new RF-NoC interconnection. In part II, we present the method of resources allocation and its reconfigurability. In part III, we study the impact of the channel shape on the transmission, and we present the power levels required to ensure performant communications.

\section{ALLOCATION OF SPECTRUM RESOURCES}

Using the principle of spectrum sharing, the maximum number of simultaneous communications in full duplex between $\mathrm{N}$ clusters is reachable if the number of channels is set to $\mathrm{N}^{*}(\mathrm{~N}-1)$. Frequency multiplexing is used for this application where a portion of total spectrum is allocated for each cluster communication. However, in case of FDMA (Frequency Division Multiple Access) modulation [9][10], the number of carriers should be limited to avoid subcarrier interferences that degrade the signal to noise ratio. Moreover to allow data rate and message recipient reconfiguration, this solution needs to reconfigure the RF part, including the frequency of the local oscillator and the bandwidth of the system, that is quite complex and power consuming.

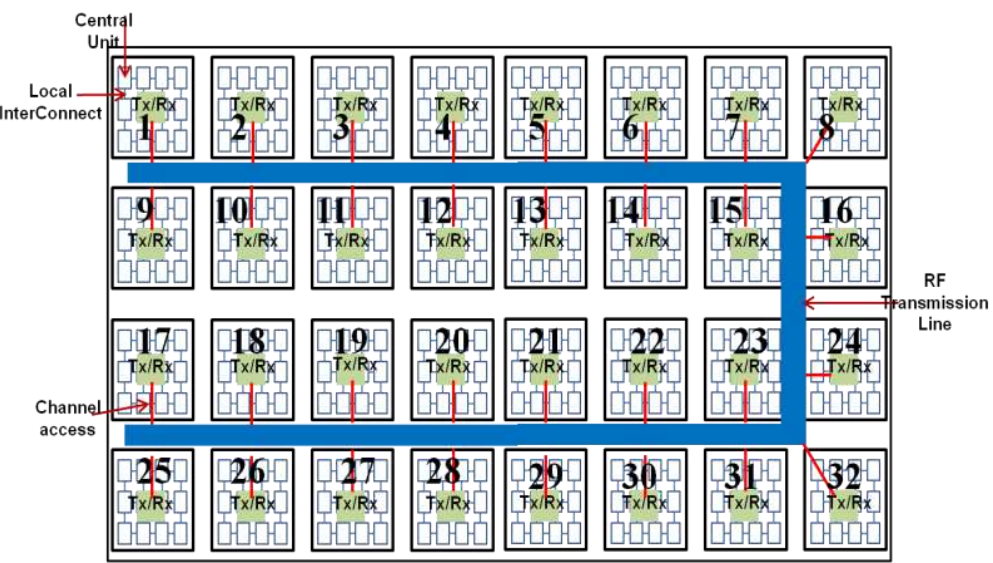

Figure 1: General MPSOC architecture, based on the RF interconnect approach. 
The OFDMA modulation scheme has been proposed in [8] instead of the FDMA modulation, to divide the available bandwidth into as non-interferent subcarriers as necessary. Using this modulation, we achieve the maximum simultaneous transmissions over the whole band without interference between carriers. This mechanism allows for optimal occupancy of the band and doesn't need the reconfiguration of the RF part; every RF part of Tx/Rx will need to be wideband but not reconfigurable to perform flexible communications.

Since the OFDMA signal is based on FFT and IFFT, the total number of subcarriers that ensure communications between all $\mathrm{Tx} / \mathrm{Rx}$, at the same time, should be equal to $2^{\mathrm{n}}$. $\mathrm{n}$ is determined from the total number of possible transmission by $2^{n}>N^{*}(N-1)$. With $B$ the available frequency band, each subcarrier is $\frac{B}{2^{n}}$ wide.

In this configuration, two transmission scenarios are allowed:

- A high data rate transmission: When only one cluster transmits information, it can benefit from high-speed transmission. Indeed, in this case, all the subcarriers can be allocated for this transmission.

- A low data rate transmission: It occurs when many clusters transmit data at the same time. In this case, the subcarriers are shared between all transmissions according to the requirements.

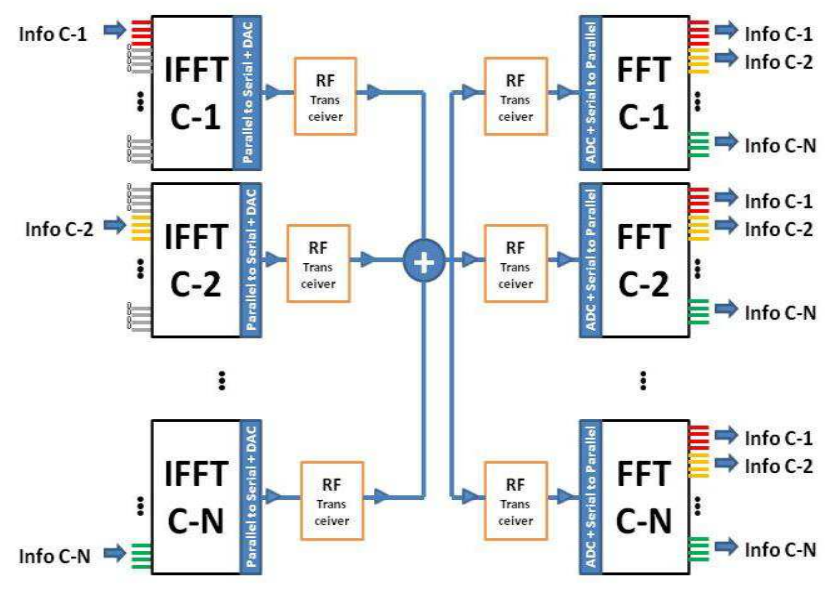

Figure 2: Allocation scheme based on OFDMA.

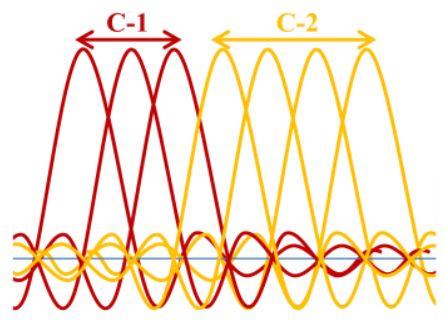

Figure 3: Subcarriers sharing with OFDMA.
In the event of a RF architecture which is composed of 32 $\mathrm{RF}-\mathrm{NoC}$ [8] interfaces with their own $\mathrm{Tx} / \mathrm{Rx}$ that provide communications between 32 clusters through a transmission line, and to allow all clusters to communicate with each other simultaneously and in both directions, 992 simultaneous transmissions possible can occur. The system needs 1024 subcarriers. Assuming $20 \mathrm{GHz}$ of bandwidth (limited in this study by the technology), the width of a subcarrier is 19.531MHz.

In this configuration, we can increase the rate for each transmission by increasing the number of subcarriers and/or by using higher order modulation. The minimum and maximum reachable rates are shown in the table-I.

TABLE 1

BIT RATES

\begin{tabular}{|c|l|l|}
\hline $\begin{array}{c}\text { Over each subcarrier } \\
(19.5 \mathrm{MHz})\end{array}$ & BPSK & $19.5 \mathrm{Mbps}$ \\
\cline { 2 - 3 } & 64QAM & $117 \mathrm{Mbps}$ \\
\hline $\begin{array}{c}\text { Over the full band } \\
(20 \mathrm{GHz})\end{array}$ & BPSK & $20 \mathrm{Gbps}$ \\
\cline { 2 - 3 } & 64QAM & $120 \mathrm{Gbps}$ \\
\hline
\end{tabular}

We note that, any intermediate solution is made possible because a digital reconfigurability allocation of subcarriers and modulation is feasible thanks to the OFDMA modulation.

\section{CHANNEL OPTIMIZATION.}

We evaluate the levels of required powers in the worst cases to size the $\mathrm{Tx} / \mathrm{Rx}$ circuits and optimize their characteristics.

\section{A. Receiver sensitivity.}

We evaluate the receiver sensitivity for a bit error rate set to $10^{-8}$ and for a noise factor of the LNA (Low Noise Amplifier) supposed to be equal to $3 \mathrm{~dB}$ over the whole frequency band.

The sensitivity is computed for the two extreme transmission cases:

- Full band transmission.

- Transmission over one subcarrier.

Two types of digital modulations are considered:

- $\quad$ BPSK (Binary Phase shift keying).

- 64QAM (Quadrature Amplitude Modulation).

Table-II shows the sensitivity values for these configurations.

TABLE II

RECEIVER SENSITIVITY

\begin{tabular}{|c|c|c|c|}
\hline \multicolumn{4}{|c|}{ Receiver sensitivity $(\mathrm{dBm})$} \\
\hline $\begin{array}{c}\text { Transmission over the } \\
\text { full band B=20GHz }\end{array}$ & $\begin{array}{c}\text { Transmission over one } \\
\text { subcarrier } \Delta \mathrm{f}=19.531 \mathrm{MHz}\end{array}$ \\
\hline 64 QAM & BPSK & 64 QAM & BPSK \\
\hline-44 & -58 & -74 & -88 \\
\hline
\end{tabular}




\section{B. Transmission optimization.}

Considering fig. 1 , and a distance between two $T_{x} / R_{x}$ of $8 \mathrm{~mm}$, the total length of the line is $120 \mathrm{~mm}$.

In the case of direct coupling (fig.4a) through the line, the presence of multiple $T_{x} / R_{x}$ affects the characteristics of the transmission line, where multiple reflections appear along the line at the interconnect points. To overcome these problems, we used the capacitive coupling to access the line [11][12][13][14] (fig.4b).This method consists in transmitting a signal between two conductors, without any physical link: a gap between the $\mathrm{Tx} / \mathrm{Rx}$ and the transmission line represents a coupling capacitance that provides the injection of the signal in the propagation channel. By using this method the characteristics of the transmission line are expected to be rather invariant over the whole frequency band, therefore less reflections phenomena appears.

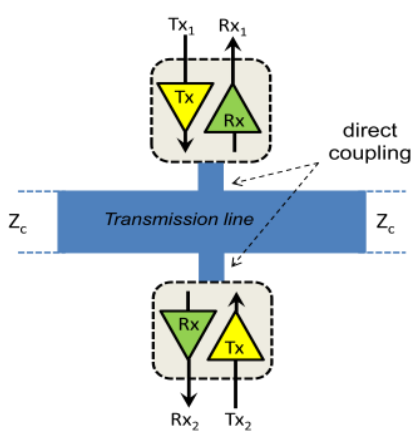

(a)

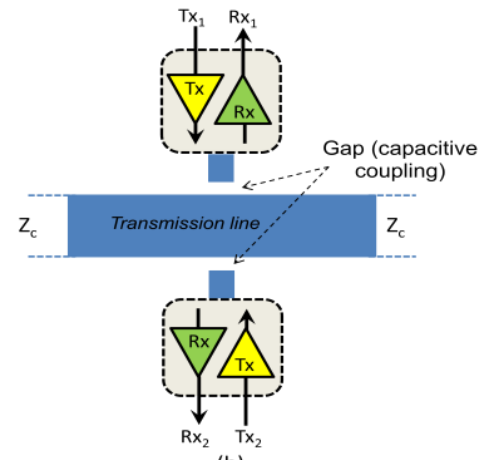

(b)
Figure 4:typical scheme of a direct coupling (a) and a capacitive coupling (b).

In our study, we use a microstrip transmission line (MTL) as propagation channel. Concerning the substrate properties, they can be summarized as follows:(using a technology delivered by NxP Semiconductors company) height $\mathrm{H}=8,783$ $\mu \mathrm{m}$; permittivity $\varepsilon_{\mathrm{r}}=4,2$, loss tangent $\operatorname{tg} \delta=2 \cdot 10^{-4}$. In order to minimize the metal loss, we use a transmission line having a characteristic impedance equal to $30 \Omega$. We evaluate the transmission coefficient $\left(S_{\mathrm{ji}}\right)$ between the transmitter $\mathrm{i}$ and the receiver j. The Fig. 6 shows the variation of $S_{j i}$ for the farthest $\mathrm{Tx}$ and $\mathrm{Rx}\left(\mathrm{Tx}_{1}\right.$ and $\mathrm{Rx}_{32}$ in the case of $\mathrm{U}$ shape of the fig.1).

To measure the linear attenuation, we place two ports at both ends of a line and we set their impedance equal to the characteristic impedance $\mathrm{Zc}$ ( $30 \Omega$ in our case) of the line to ensure maximum transmission. The linear attenuation ranges from 0.2 to $0.3 \mathrm{~dB} / \mathrm{mm}$ in the $\{20-40\} \mathrm{GHz}$ frequency band. The coupling capacitance between the $\mathrm{Tx} / \mathrm{Rx}$ and the transmission line, that optimize transmission has a value equal to $30 \mathrm{fF}$.

The fig.6 shows that the lowest value of transmission coefficient $S(32,1)$ is $-69 \mathrm{~dB}$.

Then, we calculate the minimum required transmission power corresponding to this value of $\mathrm{Sji}$ and to the values of sensitivities presented in Table I. The values of the required transmission power are relatively high
To improve the level of communication between the different clusters of the circuit, we opt to change the shape of the transmission line, especially the maximum distance between the farthest clusters without degrading the transmission path (in term of desadaptation). To achieve this goal, we use a cross transmission line (fig.5). This line shape has a length of $80 \mathrm{~mm}$ (distance between the cluster 1 and the cluster 32). The cross provides an additional division of the transmitted power at the crossing point, but the gain provided by the reduction of the maximum distance stay more important. The evaluation of the transmission coefficient $\mathrm{S}(32,1)$ is shown in fig. 6 (in blue dotted line).
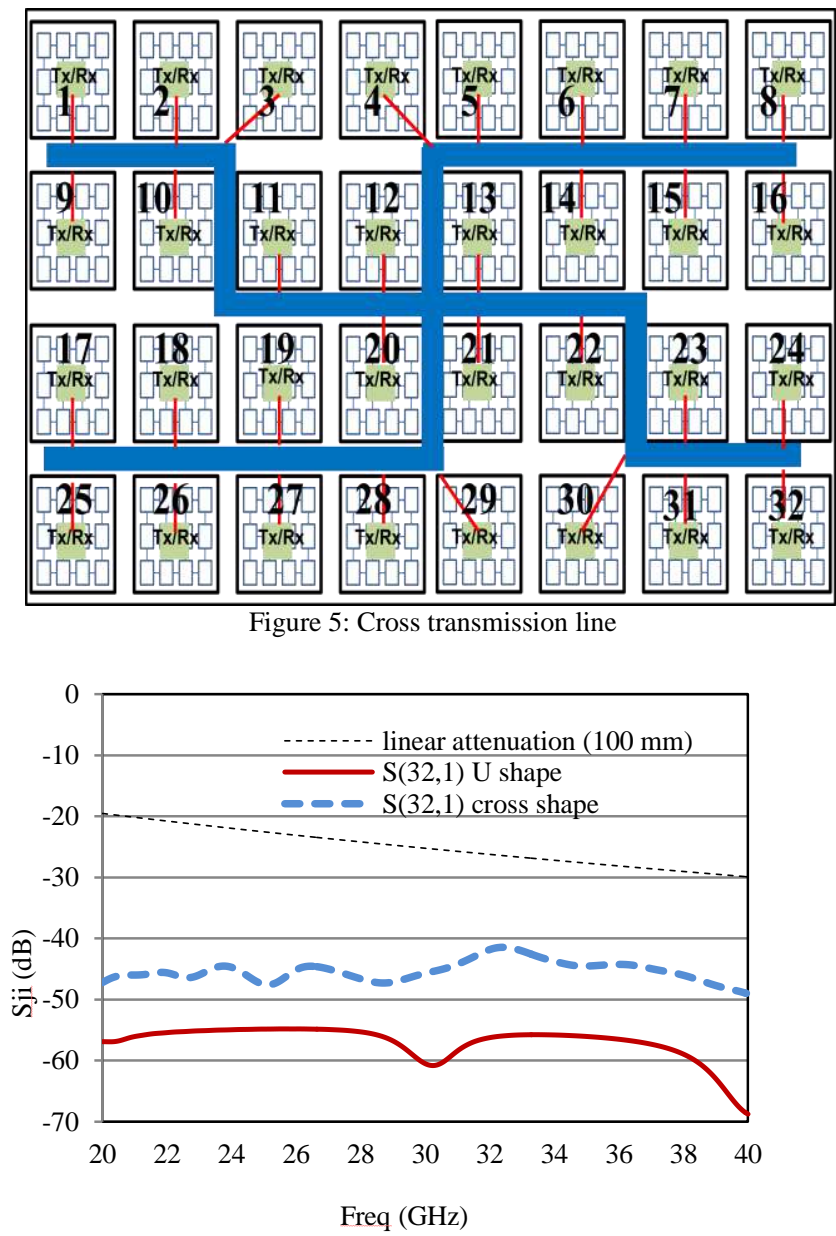

Figure 6: Linear attenuation and transmission coefficients $\mathrm{Sj}$ between Tx1 and Rx32 in case of $U$ shape and Cross shape of the line

TABLE III

REQUIRED TRANSMISSION POWER (in worst cases)

\begin{tabular}{|c|c|c|c|c|}
\hline & \multicolumn{4}{|c|}{ Minimum transmission power $(\mathrm{dBm})$} \\
\hline $\begin{array}{c}\text { Transmission } \\
\text { band }\end{array}$ & $\begin{array}{c}\text { Transmission over } \\
\text { the full band } \\
\mathrm{B}=20 \mathrm{GHz}\end{array}$ & \multicolumn{2}{|c|}{$\begin{array}{c}\text { Transmission over each } \\
\text { subcarrier } \Delta \mathrm{f}=19.531 \\
\mathrm{MHz}\end{array}$} \\
\hline $\begin{array}{c}\text { Numeric } \\
\text { modulation }\end{array}$ & 64 QAM & BPSK & 64 QAM & BPSK \\
\hline U Shape & 25 & 11 & -5 & -19 \\
\hline Cross Shape & 5 & -9 & -25 & -39 \\
\hline
\end{tabular}


As shown in fig. 6 the transmission level increases from -69 $\mathrm{dB}$ to $-49 \mathrm{~dB}$ in the worst case (the longest distance traveled by the signal) which greatly reduces the required transmission power (Table-III).

\section{Channel equalization}

In order to study the effect of the channel composed of the line and its multiple access on the transfer of information in the system, we perform a co-simulation (circuit-system) using the ADS software, for a transmission based on OFDMA modulation where all circuits are considered ideal except the transmission line.

As shown in fig.6, the level of transmission is not constant over the whole frequency band leading to an erroneous reception of transmitted data if not equalized.

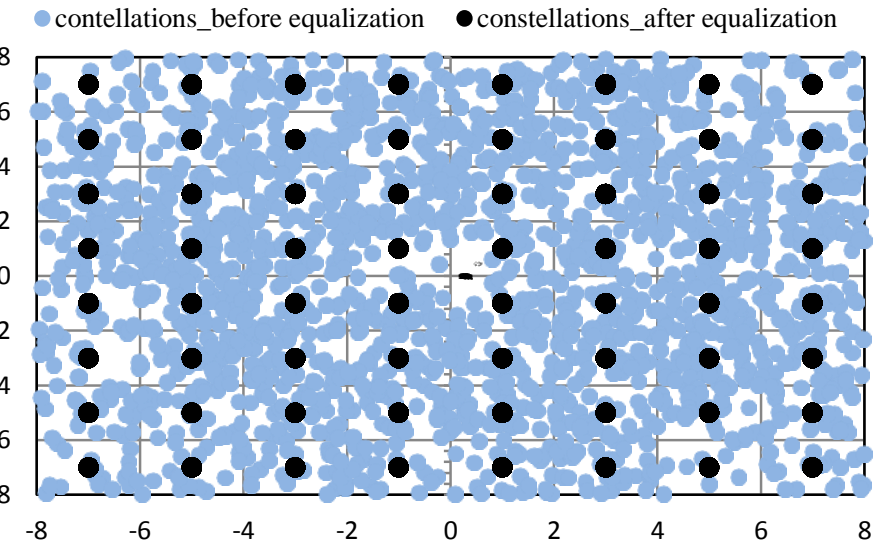

Figure 7: Constellations before and after channel equalization.

To overcome this channel effect, we require an estimation of the channel by generating a training sequence that is known by the transmitter and the receiver simultaneously.

Thanks to this sequence the receivers can calculate the transfer function of the transmission channel and perform equalization of the signal before demodulation.

We note that this training sequence will be generated only once during the system boot as the channel is static (invariant in time). As shown in fig.7, after Zero-Forcing equalization, the constellation is perfectly corrected (in the case of ideal transceivers/receivers).

\section{CONCLUSION}

In this paper we have sized a RF intra-chip communication based on OFDMA modulation. This solution presents many advantages such as providing flexible and highspeed data transmission and variable allocation of frequency band. We have shown the effect of the transmission line on the received data and their level. We also study in this paper the effects of the RF channel shape on the transmission level and the minimum transmission power needed. Finally, we have shown that this configuration needs a channel equalization; its implementation allows to escape the undesired effects of the signal propagation. Our future work is dedicated to study a new interconnect access method to the transmission line in order to obtain a much weaker attenuation through the propagation channel.

\section{ACKNOWLEDGMENT}

This work is supported by the 2012 INS program of the French National Research Agency: ANR-GUI-AAP-05. We would like to thank NXP Semiconductors for providing us their technology.

\section{REFERENCES}

[1] ITRS, 2009 edition, Interconnect.

[2] M. Brière, B. Girodias, Y. Bouchebaba, G. Nicolescu, F. Mieyeville, F. Gaffiot, I.O'Connor, "Design and behavioral modeling tools for optical network-on-chip", proc. of DATE'04, 2004.

[3] M-C F. Chang, I. Verbauwhede, C. Chien, Z. Xu, J. Kim, J. Ko, Q. Gu, B-C. Lai," Advanced RF/Baseband Interconnect Schemes for inter- and intra-ULSICommunications ", IEEE Transactions on Electron devices, Vol. 52, n², July 2005.

[4] Chang, M.F.; Cong, J.; Kaplan, A.; Naik, M.; Reinman, G.; Socher, E.; Tam, S.-W.," CMP network-on-chip overlaid with multi-band RFinterconnect ", IEEE 14th International Symposium on High Performance Computer Architecture, HPCA 2008, pp.192-202, 16-20 Feb. 2008 .

[5] E. Socher, M. F. Chang, " Can RF Help CMOS Processors? ", IEEE Communications Magazine, Vol.45, Issue 8, pp. 104-111, August 2007.

[6] H. Ito, M. Kimura, K. Miyashita, T. Ishii, K. Okada, K. Masu, "Bidirectional- and Multi-Drop-Transmission -Line Interconnect for Multipoint-to-Multipoint On-Chip Communications" IEEE Journal of Solid State Circuit, Vol.43, n 4 , April 2008.

[7] B. A. Floyd, C. M. Hung, and K. K. O, "Intra-chip wireless interconnect for clock distribution implemented with integrated antennas, receivers and transmitters," IEEE Journal of Solid-State Circuits, vol. 37, pp. 543551, May 2002.

[8] E. Unlu, M. Hamieh, C. Moy, M. Ariaudo, Y. Louet, E. Bourdel, F. Drillet, A. Briere, J. Denoulet, A. Pinna, L. Zerioul, B. Granado, P. Garda, F. Pêcheux, C. Duperrier, S. Quintanel and O. Romain, " An OFDMA Based RF Interconnect for Massive Multi-core Processors", accepted in NOCS2014, Ferrara Italy, Sept. 2014.

[9] M. Rouvi'ere, E. Bourdel, S. Quintanel, and B. Granado, "Vhdl-ams model of rf-interconnect system for global on-chip communication," in Forum on specification \& Design Languages - FDL 2010, 2010.

[10] E. Socher and M. F. Chang, "Can rf help cmos processors?" EEE Communications Magazine, vol. 45 - Issue 8, pp. 104-111, 2007.

[11] S.-C. Wong et al., "An empirical three-dimensional crossover capacitance model for multilevel interconnect VLSI circuits," IEEE Trans. Semicond. Manuf., vol. 13, no. 2, pp. 219-227, May 2000

[12] M-C F.Chang, V.P.Roychowdhury, L.Zhang, H.SHIN, Y.QIAN, "RF/Wireless Interconnect for Inter- and Intra-Chip Communications", Proceedings of the IEEE,Vol.89, n²4, April 2001.

[13] M. Sun, Y. P. Zhang, "Performance of inter-chip RFInterconnect using CPW, capacitive coupler, and UWB Transceiver," IEEE Trans. Microwave theory and tech.,vol. 53, no. 9, September 2005.

[14] Y.C. Mombo Boussougou, T. Le Gouguec, Y. Quer6, D. Le Berre, P.M. Martin, F.Huret, "Electromagnetic analysis of RF interconnect", 12th IEEE Workshop Signal Propagation on interconnects, 2008. SPI 2008. 